\title{
A TRIANGULAÇÃO FORMAL E ESTILÍSTICA NA TRADUÇÃO POÉTICA E OS CASOS DE MÉTAMORPHOSE DES YEUX DE PHILIS EN ASTRES, DE GERMAIN HABERT E DE MURDER OF GONZAGO EM HAMLET
}

\section{Lawrence Flores Pereira}

Em seus comentários à tradução das duas cenas finais do Fausto, Haroldo de Campos (1981, p. 101) revela um tipo de instância tradutória que surge de uma experiência comum entre tradutores de poesia. Ele ali descreve como a ressonância poética de Morte $e$ vida severina operou um trabalho silencioso na sua tradução dos cantos lúgubres dos Lêmures. Sua preocupação de deixar no texto a rubrica do contexto linguageiro barrocopopular e grotesco levou-o a uma atividade imaginativa de "recaptura" do pitoresco e do pictórico-poético encontradiço tanto na tradição popular brasileira como em poetas como Cabral de Melo Neto. Haroldo anota ali que a tradução é um "canto paralelo" que "não possui apenas a voz do original, mas [...] outras vozes textuais" (p. 191). O que ocorre, para usar um termo haroldiano, é um ato inspiracional "plagiotrópico" que funciona como que respondendo a topicalidades intensas no ato de leitura. A triangulação proposta por Haroldo religa, finalmente, a dicção cabralina com suas próprias escolhas tradutórias do "Enterramento" no Fausto, ou seja, Cabral se consubstancia ou ainda se enxerta indelevelmente à tradução como se houvesse uma plataforma comum aos dois textos. Haroldo trata do assunto como de um sistema de "ecos", e, no caso específico do canto dos Lêmures, ele crê que Goethe teria deixado ressoar os ecos da canção dos coveiros no quinto ato de Hamlet.

A pick-axe, and a spade, a spade

For and a shrouding-sheet:

$O$, a pit of clay for to be made

For such a guest is meet.

Numa tradução que fiz de Hamlet há alguns anos, estava ciente de que as sugestões de Haroldo de Campos em seu post scriptum "Transluciferação mefistofélica" estavam desde o início reverberando em minha experiência tradutória com William Shakespeare. Digo "reverberando" por saber que algumas cenas de Hamlet, como a dos coveiros ou 
ainda a de alguns solilóquios de Hamlet e da peça dentro da peça (apenas para mencionar alguns exemplos), teriam de ser reativados através de estilísticas combinatórias que poderiam ser definidas, respectivamente, como grotesco-barroca, demoníaco-irônicoinsinuante e barroco-retórico-estilizada. Um exemplo típico de ressonância acabou ocorrendo justamente na passagem que interessa a Haroldo de Campos. Quando cheguei à seguinte solução, ficou claro que as ressonâncias intertextuais haviam feito um círculo completo, retornando, novamente, a João Cabral de Melo Neto.
Com pá e pá e enxada
E co'um sudário fino
É bom a cova enlameada
Abrir para o novo inquilino.

Estas observações ilustram como funciona a memória intertextual do tradutor e o modo como ela é reativada na tradução. No entanto, o sistema de ecos se torna particularmente agudo quando há coincidência numérica e estrutural dos tipos de verso usados no "modelo" e na tradução. No caso específico que me interessa aqui, trata-se do impacto indireto que a tradução de um poema do século XVII francês, em particular, da chamada geração "barroca" teve, estilisticamente, na tradução da peça The murder of Gonzago, ou seja, na peça-dentro-da-peça que, numa mîse en abyme notável, se encontra no centro do Hamlet shakespeariano, e cujo estilo e gênero poético-dramático altamente metaforizado e alegórico está em aberto contraste com as características intrínsecas do "coloquial" pentâmetro iâmbico branco adotado por muitos dramaturgos elisabetanos. Gostaria, portanto, nas páginas seguintes, de ilustrar as "semelhanças" formais, estilísticas que estes dois "poemas" compartilham, retomando, na verdade, um caminho que de modo algum era óbvio quando iniciei a tradução tanto de um quanto de outro.

Antes, contudo, é necessário lembrar que toda a discussão que se segue pressupõe minha adoção, para a tradução de Shakespeare, do alexandrino ou ainda do dodecassílabo. Discuti essa adoção anteriormente em Pereira (2009). Perguntava-me, especificamente, como era possível encontrar certa naturalidade ou ainda certa comunicabilidade do verso vocalizado. Minha dúvida naquele texto sobre a eficácia das traduções decassilábicas para a tradução do pentâmetro iâmbico dramático (mas somente dramático) se originava não em minha predileção pela forma ou ainda pela tradição do alexandrino, mas nos resultados da 
experimentação tradutória com várias formas. Essas experiências antecederam o projeto de tradução de Hamlet e me levaram, gradualmente, a decidir por um verso que dava mais espaço de manobra para traduzir um fraseado que oscilasse melhor entre a poesia e prosa, dualidade que é a essência do pentâmetro iâmbico de Shakespeare. Não considerei em nenhum momento esta predileção como algo absoluto, pois sabia que, além de não ter nada de nova, talvez não fosse a melhor solução para poemas líricos ou até mesmo narrativos. O alexandrino foi usado anteriormente para a tradução do pentâmetro iâmbico: alguns dos tradutores o haviam domado para o teatro, naturalizando-o no português, desenvolvendo aqui e ali possibilidades de acentuação que se adaptassem ao português. No entanto, como argumento principal para o uso desta forma na tradução de Shakespeare, eu me lembrava do problema, bem conhecido de tradutores de língua inglesa, de honrar diversos elementos: a coloquialidade que permite uma rápida compreensão, a decisão de evitar o “empolamento" excessivo, de evitar o "enjambement sistemático" que desfigura o sistema contrastivo, na poesia de Shakespeare, entre "end-stopped verse" e seu contrário, o verso com enjambement. Mais importante do que todos estes elementos, ao meu ver, era realmente ganhar algum espaço adicional que permitisse o uso mais intensivo de palavras mais longas - palavras estas que os tradutores "decassilábicos" são geralmente forçados a exilarem de suas traduções. Isto prometia uma vantagem imensa no caso das peças de Shakespeare, cuja opulência vocabular é bem conhecida.

Em 2002 traduzi, então, Métamorphose des yeux de Philis en astres, de Germain Habert (1615-1654), poema publicado pela primeira vez em 1639, e um dos mais apreciados na primeira metade do século XVII. ${ }^{1}$ Germain Habert era contemporâneo de Corneille e foi um dos membros fundadores da Académie, e também um dos membros da comissão que mediou a discussão que veio a ser chamada de Querelle $d u$ Cid sobre a peça de Corneille e as regras do teatro. Pouco se sabe sobre sua figura além do que recebemos em duas de suas obras: o poema aqui analisado e uma biografia que escreveu no final da vida sobre o cardeal Bérulle.

Métamorphose des Yeux de Philis en astres está aparentada às obras de outros poetas dessa geração, em particular ao poema Temple de la Mort, de Philippe Habert, o irmão de Germain. O poema de Philippe Habert recebeu uma tradução até mesmo para o

\footnotetext{
${ }^{1}$ No registro da Biblioteca Nacional consta erroneamente o nome de Rotrou como autor do poema.
} 
inglês ainda na década de 1660, mostrando o vigor daquela poesia dentro de certos círculos. Os que conhecem bem o estilo "corrido" e altamente sintático de Corneille entenderão o tipo estilístico desse poema pelo menos em sua qualidade oratória. O poema de Germain Habert pertence àquela tradição ovidiana do século XVII francês que se mesclou, por volta da metade do século XVI, à igualmente forte tradição da pastoral. ${ }^{2} \mathrm{O}$ poema é considerado por críticos diversos um típico poema "precioso", o termo que designa um movimento aristocrático dos frequentadores refinados dos salons da Marquesa de Rambouillet. A associação com o estilo precioso não contribuiu para a conservação da fama de seu poema, visto que Molière se encarregou de satirizar as précieuses ridicules. Rastreando a fortuna crítica de Philis, temos um primeiro momento entusiasta, que logo é sucedido por posturas bem mais críticas desde a segunda metade do século XVII. Mas o que gerou um silenciamento do poema foi sem dúvida o veredito de Voltaire (1894), em Siècle de Louis $X I V$, o qual acabou por coibir qualquer possibilidade posterior de investigação crítica deste poema.

CERISY (Germain Habert de) era do tempo da aurora do bom gosto e do estabelecimento da Academia francesa. Sua Metamorfoses dos olhos de Filis em astros foi anunciada como uma obra-prima, e deixou de parecer sê-lo quando chegaram os bons autores. Morto em 1655 .

Mas poucas décadas antes, o poema era visto como uma obra-prima. Em 1665, Boursault, intuindo as possibilidades teatrais da história, escrevia uma peça com o mesmo nome. No seu "Avis au lecteur" escreveu

A Metamorfose dos Olhos de Fílis em astros é um poema que obteve tanta reputação e que deu tanta glória ao falecido senhor Abade de Cerisy, que era o seu autor, que há poucas pessoas que se empenham em amar as belas coisas que não o tenham lido repetidamente para conhecer mais da metade de memória (Boursault, 1665).

Esse impacto perdurou também para além do período de Habert. La Fontaine explorou e aperfeiçoou o estilo burilado de Habert em seu Adonis. E o estilo simbólico e ingênuo de Habert se faz sentir até mesmo nas Promenades de Port-Royal des Champs, de Racine. Se hoje é difícil compreender o imenso sucesso desse poema em sua época, isto é porque a estética clássica vetou o tipo de combinação imagética alegórica intensa sobre o qual o

\footnotetext{
${ }^{2}$ V. Chatelain, 2008. Muitas das apreciações de Chatelain, embora aplicadas à segunda metade do século
} XVII, encontram ressonância na poesia de Habert. 
poema estava montado. Um exemplo desse desgosto com tudo o que a geração anterior havia escrito, com o seu uso peculiar de metáforas e alegorias e outras figuras, está documentado na Manière de bien Penser, de Bouhours (1715), onde se encontra um diálogo entre os personagens fictícios Filanto e Eudóxio, que colocam o poema de Habert no centro da discussão opondo a antiga escola do estilo florido e das metáforas contínuas e o novo espírito, que detesta os "brilhantes" e a afetação. A discussão descrita por Bouhours dá a medida de uma ruptura literária que evitará os exageros retóricos e a linguagem antitética, privilegiando o "naturel". No entanto, o preciosismo literário, em sua qualidade estilística, não era de modo algum uma novidade francesa. Ela tinha longas raízes na Itália, e estava associada a Tasso assim como à vasta moda ovidiana que, em sucessivas vagas, nutriu diversas gerações de estudantes na Europa (Rousset, 1961).

Escrito em alexandrinos clássicos, o poema conta a história de como Fílis é vítima do olhar cobiçoso do Sol, o qual, enciumado, provoca a morte de Dáfnis, amante da heroína. A consequência dramática desta intervenção divina é a "dissolução" física de Fílis que retorna ao "elemento" primevo, ou seja, à fonte materna onde ela é apresentada no início do poema numa fusão com a encantadora flutuação especular do luminoso "canal". Eis aqui uma passagem com a tradução ao lado.

C'est là, par un Chaos agreable, \& nouveau Que la Terre \& le Ciel se rencontrent dans l'eau, C'est là, que l'oeil souffrant de douces impostures, Confonds tous les objets avecque leurs figures, C'est là, que sur un arbre il croit voir les poissons, Qu'il trouve les oyseaux auprez des ameçons, Et que le sens charmé d'une trompeuse Idole, Doute si l'oyseau nage, ou si le poisson vole. C'est là qu'une Bergere estalant ses attraits, Fait en se regardant de plus nobles portraits, Quand le genou courbé sur les fleurs du rivage, Elle vient arrouser celles de son visage, Qui remplissant les eaux de feux \& de clartez, Pour un peu d'ornement leur rend mille beautez.
É lá que, por um Caos, agradável \& fulgente, Se encontram terra e céu na lúcida corrente, É lá que a vista, presa a doces imposturas, Confunde as coisas todas com suas figuras. É lá que crê enxergar os peixes sobre os galhos Que encontra as aves leves perto dos cascalhos, E que o olhar à mercê de deusa enganadora Não sabe se a ave nada ou se o peixe revoa. É lá que uma pastora exibindo amavios Esboça ao se olhar os mais nobres feitios, Quando, o joelho curvado às flores da ribeira, Rega as pétalas brancas da face fagueira, Que, preenchendo a fonte em fogos \& fulgores, Por qualquer atavio dá feixes de mil cores.

Se a história possui certa simplicidade e candura, essa visão tende também a ser enganadora. A simplicidade é em parte contaminada por uma corrente subterrânea simbólica que sugere o interesse de Habert em explorar os paradoxos que se originaram, no pensamento contemporâneo, das discussões sobre a relação entre o homem e Deus, e as 
tensões entre a vida efêmera do homem e a vida eterna. O paradoxo mais notável do poema: o deus sol que aparece como fadado simultaneamente a repetir o "movimento eterno" próprio dos astros sempiternos, e que, ao mesmo tempo, está preso a uma "imobilidade" insuportável e entediante. Em outras palavras, ele é a figura do poder sobrehumano (e também monárquico) que padece de uma fraqueza: a de querer romper os limites de sua eternidade e partilhar com os homens a natureza limitada e mortal — isto é, o ponto de vista que percebe a eternidade como um tédio eterno. $\mathrm{O}$ interesse de Habert por estas questões é, de fato, um traço de seu preciosismo. Entretanto, é possível flagrar certa profundidade no assunto quando pensamos que as teorias monárquicas dos séculos XVI e XVII gostavam de dramatizar o paradoxo da realeza, dividida entre humanidade e divindade e, por isto mesmo, limitada dentro de sua própria vastidão. Finalmente, o poema incorpora de modo mais tópico e surpreendente as discussões sobre a atomística do século XVII, possivelmente figurando algumas das preocupações de Gassinder e de outros teóricos do período (Clericuzio, 2000). Ao ser atingido pela violência do sol, Dáfnis sofre uma transformação corporal que é descrita como uma desagregação atomística. A transformação corporal mítica, de Ovídio, recebe a mediação da explicação atomística segundo a qual os corpos são formados de micropartículas.

Ces atomes vivans, durables estincelles, Petit corps, qui des corps sont les ames mortelles, Invisibles liens, qui jusques au trépas Attache ce qu'on voit à ce qu'on ne voit pas, Les Esprits accourus en troupes mutinées, Font cent tours \& retours, en leurs routes bornees, E par leurs cours divers esbranlans tout le corps, D'un movement confus agitent ses ressorts. On dirait que son ame en ce mortel orage Cherche de tous costez à se faire un passage, Qu'elle frappe par tout pour rompre sa prison, \& se sauver des feux qui brusle sa maison. Ses yeux sont devenus deux sanglantes Cometes Qui d'un cruel trespas sont les tristes Prophetes, Son corps avant la mort a demy consumé, Paroist dans sa languer un squellette enflammé.
Tais átomos febris, chispas atemporais, Corpinhos donde nasce a alma dos mortais, Indistintas junções que até a morte imprevista Ligam o que se vê ao que se esquiva à vista; Em tropa amotinada, os Espíritos leves Vão e vem, voltejando, em suas rotas breves, E lhe abalam o corpo, aos saltos, como bolas, Com confusas moções agitam-lhe as molas. Dir-se-ia que a alma, em pleno temporal Pra sair se debate em busca de um portal. Que ela, aos golpes, procura arrombar sua prisão E se salvar da chama a queimar sua mansão. Seu olhar se tornou um sangrento luzeiro Que de um final cruel é o triste agoureiro. Seu corpo antes do fim, lânguido, consumido Parece um esqueleto em chamas comburido.

Um dos traços estilísticos recorrentes do poema é o uso enfático de oximoros e inversões elegantes que enfatizam, para dar apenas alguns exemplos, a condição a um tempo "eterna" e "limitada" do sol ou os contrastes entre "mundo eterno" e mundo terreno, 
entre deuses e homens. Se o sol faz parte da eternidade, por outro lado ele não pode descer até a condição humana, onde é possível "sofrer os grilhões do amor". O poema é um concentrado impressionante da retórica barroca. Muitas vezes as fórmulas antitéticas, distribuídas ao longo de um verso, se acomodam dentro da separação formal entre os dois hemistíquios, produzindo efeitos variados. Na abundante metafísica amorosa destacam-se em particular os contrastes entre a resistência e a entrega (de Filis), entre o eu e o outro, assim como do eu consigo mesmo. Este último elemento é particularmente impressionante. Bebendo da tradição do mito de Narciso, Habert fundiu a história da "jovem à beira da água" com a lenda da antiguidade. Esta fusão dá lugar a uma reflexão complexa sobre o significado do amor e do próprio "reflexo" amoroso. Numa das passagens, a paixão solar é descrita como algo impossível, explorando as coincidências semânticas através de metáforas luminosas.

Ce grand feu consumant luy-mesme est consumé, Les Amours tous brillans, \& de flame \& de gloire Suivent leur prisonnier en chantant leur victoire. Et dans ce char bruslant, mais plus bruslant encor, Font de nouveaux rayons par leur plumage d'or, Avec un doux plaisir ils passent l'onde amere, Joyeux de triompher aux pays de leur Mere, Et de punir celuy, dont le jour indiscret Fit un crime public de son amour secret.
E o fogo que avassala é agora avassalado, Os amores brilhando e de chama e de glória, Seguem seu prisioneiro entoando a vitória. E nesse carro ardente e mais que o fogo louro, Fazem raios novéis de sua plumagem de ouro. Com um doce prazer passam a vaga riscosa, Felizes de triunfar no chão da mãe ditosa, E de punir o ser cujo dia indiscreto Fez um crime comum de seu amor secreto.

O uso habilidoso da cesura semântica, como no primeiro verso acima, pode ocasionalmente dar um brilhantismo particular a um pensamento. É o caso também do antepenúltimo verso abaixo. A descrição do "espelho da água", lugar primevo do sonho e do encontro com a primeira natureza, é ricamente decorado.

Au milieu de ce bois un liquide cristal En tombant d'un rocher forme un large canal, Qui comme un beau miroir, dans sa glace [ inconstante

Fait de tous ses voisins la peinture mouvante, Les secrets de son sein sont ouverts à chacun, Plus il se montre pur, plus il se rend commun, Et decouvrant son lit aux plus foibles oeillades, Il trahit la pudeur de ses chastes Nä̈ades.
No meio desse bosque um líquido cristal Ao cair de um rochedo abre um largo canal, Que como um belo espelho, em seu vidro [inconstante, Faz de todos em volta uma imagem ondulante, Seu segredo mais imo se abre a qualquer um Quanto mais puro for, mais se torna comum, E revelando o leito às fugazes olhadas Ele trai o pudor das suas castas Naiadas, 
Pela ausência de elementos realistas, o poema se inscreve quase exclusivamente no regime da fábula alegórica que modula uma série de motivos tradicionais - em particular, naquele que se encontra também no canto X das Metamorfoses. É bom lembrar que Shakespeare e La Fontaine escreveram suas próprias versões do canto X das Metamorfoses, La Fontaine em seu Adonis, Shakespeare, em Venus and Adonis. Em Shakespeare, em Habert e em La Fontaine é notável a combinação entre a amenidade pastoral elegante e a violência metamórfica das Metamorfoses ovidianas. Shakespeare adotou o estilo do final do Renascimento inglês - em particular o de Edmund Spenser, que aperfeiçoou a fábula alegórica em sua The Faerie Queene, ao passo que o estilo do Adonis de La Fontaine é derivado na maior parte da obra de Germain Habert. Pois é Germain Habert que aperfeiçoa pela primeira vez o verso corrido repleto de movimentação, legando essa técnica para La Fontaine: sua forma, sua obscuridade das imagens, suas combinações metafóricas e sua fantasia decorativa.

\section{A peça dentro da peça em Hamlet e sua tradução}

Embora seja duvidoso definir ao certo o estilo e o gênero exato da peça dentro da peça em Hamlet e o seu lugar na tradição teatral do século XVII, o fato é que ela se relaciona estilisticamente tanto com a tradição poética narrativa como com as chamadas masques, o tipo de entretenimento e de encenação festiva cortesã que fazia parte das práticas de corte do período. Shakespeare utilizou o artifício da perspectiva metateatral em suas peças com intenções diversas. O artifício havia sido usado também por dramaturgos como Kyd, Middleton, Fletcher, Beaumont, Marston e Jonson. Interessa-nos aqui a modalidade de peça dentro da peça que imita o teatro cortesão, que, como é sabido, possuía características muito diferentes do teatro "público", ou seja, o teatro cuja frequentação estava aberta ao público de Londres em teatros como o Globe ou ainda o Rose. A peça que Prospero "dirige" em The tempest possui a carga simbólico-alegórica e a estilização cerrada que eram típicas das masques. Por sua característica cortesã, as masques eram uma apresentação altamente idealizada de dilemas que envolvem a vida de um soberano ou de nobres geralmente apresentados sob a máscara de figuras míticas, simbólicas ou simplesmente elevadas. Não há nada mais impressionante do que constatar a imensa diferença da linguagem teatral de corte e da linguagem teatral nos public theatres. 
Incrementadas com música e dança, com cantos e o uso elaborado de cenários, as masques apresentavam uma imagem idealizada e respeitosa do monarca; nelas o "realismo" das peças de Shakespeare seria impróprio e ofensivo, pondo em dúvida a profundidade simbólica da figura monárquica. Mesmo assim, a peça dentro da peça, em Hamlet, contém alguns traços do gênero das masques, traços que simulam uma luta que leva finalmente à afirmação providencial da sabedoria real. Embora não apresente uma visão deferente de qualquer monarca (na verdade, ela inverte o esquema das masques), Shakespeare embute certas semelhanças nas imagens desta peça: ${ }^{3}$ o uso de referências mitológicas que aparecem logo no início, com suas perífrases como “Phoebus' cart” ou ainda o "Neptune's salt wash", com seus luxos numéricos como "thirty dozen moons" revelam a figura da periergia, ou seja, a elevação retórica de elementos relativamente simples, um engrandecimento poético. A peça dentro da peça é também escrita em dísticos rimados que, na maior parte das vezes, coincidem também como uma unidade de sentido, raramente ocorrendo transbordamento para o verso seguinte. Outra característica é o uso das formas mais diversas de inversão, desde anástrofes (ordem sintática) até cacossíntetos. Outro traço característico é o uso de sententie, ou seja, de aforismos ou máximas morais que geralmente são formuladas em combinação com certas características formais dos versos como em

\section{Purpose is but the slave to memory}

Of Violent birth but poor validity...

Ou ainda em

Where love is great, the littlest doubts are fear,

Where little fears grow great, great love grows there...

Estes comentários gerais servem para contextualizar o papel do ricochete estilístico na atividade de tradução. O fato é que, postos lado a lado, o poema de Métamorphose de yeux de Philis en astres e o "Assassinato de Gonzago" podem ser imaginados como pertencendo,

\footnotetext{
${ }^{3}$ Sigo aqui a descrição de Carol Replogle (1969, p. 150-159) sobre o estilo da peça dentro da peça.
} 
na sua microestrutura estilística, a uma tradição similar. Exemplo disso é o uso de formas contrastivas que criam uma cisão elegante no centro do verso.

\begin{abstract}
Cependant il s'avance ou le destin l'appelle
Fidèle à la Nature, à soi-même infidèle...

Porém, rumo ao destino ele caminha a esmo, Fiel à natureza e infiel a si mesmo...
\end{abstract}

Que é comparável estilisticamente a
Purpose is but the slave to memory
Of Violent birth but poor validity...
O intento não é mais que escravo da memória,
Violento ao despontar, tem curta trajetória...

Os exemplos, na verdade, abundam e explicam como, no ato de tradução, as formas de um poema "magicamente" se reconfiguram no segundo poema traduzido. A escolha que fizemos de traduzir o pentâmetro iâmbico em alexandrinos naturalmente foi crucial para que tais associações se fizessem, produzindo efeitos específicos. Compare-se, por exemplo, o quarto verso abaixo, do poema de Habert com os do quadro subsequente onde apresento um trecho da peça dentro da peça, com sua respectiva tradução.

Au milieu de ce bois un liquide cristal En tombant d'un rocher forme un large canal, Qui comme un beau miroir, dans sa glace [inconstante

Fait de tous ses voisins la peinture mouvante, Les secrets de son sein sont ouverts à chacun Plus il se montre pur, plus il se rend commun, Et découvrant son lit aux plus faibles cillades, Il trahit la pudeur de ses chastes Naïades.

\section{PLAYER QUEEN}

So many journeys may the sun and moon Make us again count o'er ere love be done. But woe is me! You are so sick of late, So far from cheer and from your former state, That I distrust you. Yet though I distrust, Discomfort you, my lord, it nothing must. For women fear too much, even as they love,
No meio desse bosque um líquido cristal Ao cair de um rochedo abre um largo canal, Que como um belo espelho, em seu vidro [inconstante,

Faz de todos em volta uma imagem ondulante, Seu segredo mais imo se abre a qualquer um Quanto mais puro for, mais se torna comum, E revelando o leito às fugazes olhadas Ele trai o pudor das suas castas Naiadas,

\section{RAINHA-ATOR}

Giros e giros sol e lua terão dado Antes que nosso amor tenha enfim terminado. Mas, ai de mim, estás há dias tão doente, Tão longe da alegria e do estado recente, Que me aflijo por ti. Porém atribulada, Não há, oh meu senhor, de inquietá-lo nada; A mulher teme muito, mesmo quando ama, 
And women's fear and love hold quantity,

In neither aught, or in extremity.

Now what my love is, proof hath made you know,

And as my love is sized, my fear is so:

Where love is great, the littlest doubts are fear.

Where little fears grow great, great love grows
Possui temor e medo em porções iguais;

Ou nenhum há dos dois ou dos dois há demais.

Mas quanto ao meu amor, já dei prova tamanha,

Quanto mais ele cresce, o temor mais se entranha.

Onde o amor é grande, qualquer dúvida é temor;

E onde os medos crescem, cresce o grande amor.

[there.

O que se vê é certa frequência, na peça dentro da peça, de um tipo de cesura do verso que produz, por sua vez, dois segmentos semânticos. Ainda que o local dessa "cesura" semântica não se posicione sempre no mesmo pé métrico (como ocorre no alexandrino), seu efeito é muito semelhante à divisão formal do verso no alexandrino em dois hemistíquios, ou pelo menos possui potencialidade de efeito estético equivalente. Eis alguns exemplos.

In neither aught, or in extremity

Or nenhum há dois dois ou dos dois há demais

Ou ainda

And as my Love is sized, my fear is so

Quanto mais ele cresce, o temor mais se entranha

Em ambos ressoa o verso citado de Fílis

Quanto mais puro for, mais se torna comum...

Formas semelhantes aparecem em outras partes do poema. Aqui o sol monárquico, impotente em sua soberania, lamenta sua condição divina que limita sua ação.

Mais voila tout d'un coup la Deesse vengée, Et du Dieu des saisons la fortune changée,

Celuy qui brusloit tout est luy-mesme enflamé, Ce grand feu consumant luy-mesme est consumé, Les Amours tous brillans, \& de flame \& de gloire, Suivent leur prisonnier en chantant leur victoire. Et dans ce char bruslant, mais plus bruslant encore, Font de nouveaux rayons par leur plumage d'or...
Mas, de repente, eis a Deusa já vingada, E do rei das sazões a fortuna alterada, Quem ontem incendiou é agora incendiado, E o fogo que avassala é agora avassalado, Os amores brilhando e de chama e de glória, Seguem seu prisioneiro entoando a vitória. E nesse carro ardente e mais que o fogo louro, Fazem raios novéis de sua plumagem de ouro... 
Gostaria de concluir assinalando que essa triangulação tradutória — onde há um texto de partida, um texto de chegada, mas também uma ressonância intermediária em uma terceira língua - não constitui a única forma de fazer ressoar certas características do original no produto final da tradução. Naturalmente, a transmissão estética de certas formas do original sofrem uma ligeira deformação que é o resultado justamente do ajuste entre as três tradições envolvidas. No entanto, a extensão do alexandrino, sua divisão interna que quase faz pensar num verso com dois versos, serviu, na tradução de Hamlet, como um lugar de passagem, já no domínio das línguas latinas, que permitiu acomodar formas perceptíveis de divisão intravérsica importantes do verso da peça dentro da peça. É desnecessário dizer que de modo algum um poema como o de Germain Habert poderia servir de modelo principal ou mesmo de sugestão para qualquer outro conjunto de versos em Hamlet, pela simples razão que Shakespeare, ao introduzir em Hamlet uma peça dentro da peça, contava com a capacidade de seu público de distinguir uma versificação hiperpoética e alegórica da versificação mais "prosaica" do seu pentâmetro iâmbico branco.

\section{Referências bibliográficas:}

BOUHOURS, Dominique. La manière de bien penser dans les ouvrages d'esprit. Mich. Brunet, 1715.

BOURSAULT, Edme. La métamorphose des yeux de Philis: changez en astres, pastorale représentée par la troupe royale, et mise au théâtre. Paris: N. Pépingué, 1665. http://gallica.bnf.fr/ark:/12148/bpt6k74001q

CAMPOS, Haroldo de. Deus e o Diabo no Fausto de Goethe. São Paulo: Perspectiva, 1981.

CHATELAIN, Marie-Claire. Ovide savant, Ovide galant: Ovide en France dans la seconde moitié du XVIIe siècle. Paris: Champion, 2008.

CLERICUZIO, Antonio. Elements, principles and corpuscles: a study of atomism and chemistry in the seventeenth century. Berlim: Springer, 2000.

HABERT, Germain (1615-1654). Métamorphose des yeux de Philis en astres [par Rotrou]. Dernière édition. Paris: A. de Sommaville, 1649. http://gallica.bnf.fr/ark:/12148/bpt6k711498

PEREIRA, Lawrence Flores. Notas sobre o uso do alexandrino na tradução do drama shakespeariano. In: Literatura traduzida e literatura nacional. GUERINI, Andréia et. al. (orgs.) Rio de Janeiro: 7 Letras, 2009. p. 145-158. 
REPLOGLE, Carol. Not parody, not burlesque: the play within the play in Hamlet. Modern Philology 67, nº 2 (November 1, 1969): 150-159.

ROUSSET, Jean. Anthologie de la poésie baroque française. Bibliothèque de Cluny. Paris: A. Colin, 1961.

. Dernier regard sur le baroque; suivi de, le geste et la voix dans le roman. Les Essais. Paris: J. Corti, 1998.

La litterature de l'age baroque en France: Circé et Le Paon. Paris: J. Corti, 1954.

SHAKESPEARE, William. Hamlet. Org. Ann Thompson and Neil Taylor. Arden Shakespeare, 2006.

VOLTAIRE. Le siècle de Louis XIV par Voltaire suivi du catalogue des écrivains et artistes français. Paris: Armand Colin, 1894. 